\title{
Evaluating the Impact of In-Home Behavioral Health Services on Housing First Residents' Emergency Room and Inpatient Utilization
}

\author{
Ryan F. Savino \\ Elizabeth A. Bowen \\ Andrew Irish \\ Amy K. Johnson
}

\begin{abstract}
Individuals experiencing chronic homelessness are highly marginalized and frequently access acute healthcare services. This program evaluation used secondary data collected from adults experiencing chronic homelessness $(n=133)$ who participated in a Housing First program offering in-home behavioral health services within a large Midwestern city. Participant demographics (e.g., gender, race, age) and data on health factors (e.g., substance misuse and mental health symptoms, and ER visits and inpatient hospitalizations) were collected at program enrollment and at 6-month and 12-month follow-ups. High proportions of missing data led the evaluators to exclude 12-month follow-up and in-home behavioral health data from the analyses. Neither inpatient nights nor ER visits changed significantly between enrollment and 6-months. Males were disproportionately hospitalized throughout the study, suggesting a need for gendertargeted services. Higher rates of hospitalization among African Americans at enrollment subsided by follow-up. Future evaluation should examine if in-home behavioral health services reduced racial health disparities. Acute care use was low overall, likely because of the stabilizing impact of housing. Data limitations suggest a need for more robust study designs to identify causal factors and to enrich our understanding of the role of behavioral health intervention within the Housing First paradigm. Results underscore the importance of using empirically-supported assessment tools to evaluate consumers' individualized needs and responsively allocate supportive services.
\end{abstract}

Keywords: dual diagnosis; emergency room; homeless; hospitalization; Housing First; in-home; SBIRT

The U.S. Department of Housing and Urban Development (HUD) revealed that 567,715 U.S. residents were homeless at a single point in time in January 2019 (Henry et al., 2020). The literature has traditionally distinguished between people experiencing homelessness chronically, episodically, or transitionally (McAllister et al., 2011). Under HUD's current definition, individuals considered chronically homeless must possess a disabling mental or physical health condition and experience either a continuous period of homelessness exceeding one year, or four or more discrete episodes of homelessness in the preceding three years, totaling 12 months or more (U.S. Department of Housing and Urban Development, 2015). This definition builds upon HUD's prior conceptualization of chronic homelessness by requiring that discrete episodes total 12 months or more (Byrne \& Culhane, 2015; Henry et al., 2020). In 2010, investigators found that homeless persons

Ryan F. Savino, LMSW, MBA, PhD Student in Social Welfare, The Graduate Center, City University of New York, New York, NY. Elizabeth A. Bowen, PhD, Associate Professor and Andrew Irish, MSW, PhD Candidate, University at Buffalo School of Social Work, Buffalo, NY. Amy K. Johnson, PhD, MSW, Research Assistant Professor, Ann \& Robert H. Lurie Children's Hospital of Chicago, Northwestern University Feinberg School of Medicine, Chicago, IL.

Copyright $@ 2020$ Authors, Vol. 20 No. 3 (Fall 2020), 675-693, DOI: 10.18060/24293

(cc) BY This work is licensed under a Creative Commons Attribution 4.0 International License. 
accounted for only $0.25 \%$ of the U.S. population, yet represented $0.5 \%$ of the nation's ER users (Ku et al., 2010). Similarly, although individuals experiencing chronic homelessness constitute only a fraction of the homeless population, they account for a majority of the group's housing and healthcare resource consumption (Aubry et al., 2013; Henry et al., 2020; Larimer et al., 2009; Wright et al., 2016).

Physical health problems, substance misuse, and mental health conditions are more prevalent among people experiencing homelessness, particularly chronic homelessness (Jaworsky et al., 2016). Risk accumulation theory attributes this population's high incidence of psychiatric and physical morbidity to overexposure to adverse life events (Lippert \& Lee, 2015; Oppenheimer et al., 2016). Barriers to preventative healthcare can exacerbate health disparities, driving frequent hospital use (Chwastiak et al., 2012; Khandor et al., 2011; White et al., 2016). Meta-regressions of persons experiencing homelessness across Western Europe and North America yield elevated random-effects pooled prevalence of $11.4 \%$ for major depressive disorder, $23.1 \%$ for a personality disorder, $12.7 \%$ for a psychotic disorder, $37.9 \%$ for alcohol dependence, and $24.4 \%$ for drug dependence (Fazel et al., 2008). People living as homeless with serious mental illnesses also make greater use of psychiatric hospitals and less use of outpatient mental health services than their housed peers (Folsom et al., 2005). Relative to a matched-comparison domiciled group, Wadhera et al. (2019) found that hospitalizations for persons experiencing homelessness were disproportionately due to mental illness (at rates of $38 \%$ vs. $13 \%$ ) and substance misuse (at rates of $14 \%$ vs. $5 \%$ ). The researchers also observed that psychiatric, but not physical illnesses, were associated with homelessness chronicity (Wadhera et al., 2019). However, improved access to ambulatory care alone, through mechanisms such as insurance coverage expansion, may not translate into wholesale acute care reductions among people contending with chronic homelessness (Hwang et al., 2013; Lin et al., 2015).

Housing First has emerged as a promising model of permanent supportive housing to address these complex health and social needs (Henwood, Hsu, et al., 2013; Rog et al., 2014). Through Housing First, consumers are not required to abstain from substances or to achieve psychiatric or medical stability to enroll in housing; instead, they are given access to a variety of supports as they work toward individualized goals and reside independently (Nelson, 2010). Housing First programs lower mortality rates (Henwood et al., 2015) and healthcare costs (Larimer et al., 2009). Housing First is also associated with increased perceptions of consumer choice and mastery-factors theorized to allay psychiatric symptom severity (Greenwood et al., 2005). Compared to usual care (outpatient mental health and substance misuse services, sobering services, and shelters), Housing First recipients spend less time homeless or psychiatrically hospitalized (Brown et al., 2016). Moreover, several landmark studies challenge the assumptions inherent to treatmentcontingent (Continuum of Care) models, with treatment-non-contingent (Housing First) program participants demonstrating either comparable or reduced mental health and substance misuse severity relative to Continuum of Care participants (Groton, 2013), as measured by the Addiction Severity Index (McLellan et al., 1980), Colorado Symptom Index (Boothroyd \& Chen, 2008), Alcohol Use Quantity Form (Sobell \& Sobell, 1992), Short Inventory of Problems (Blanchard et al., 2003), DSM-IV Alcohol Dependence 
Checklist (American Psychiatric Association, 2000), and Drug and Alcohol Follow-back Calendar (New Hampshire Dartmouth Psychiatric Research Center, 1995).

Yet the Housing First evidence base has several notable limitations (Trilling, 2016). Criticisms include an overlap between Housing First developers and evaluators - elevating the potential for conflicts of interest (Groton, 2013), limited evidence regarding the efficacy of Housing First in reducing substance misuse (Clifasefi et al., 2016), methodological inconsistencies in outcome monitoring (Groton, 2013; Trilling, 2016), and overgeneralization in Housing First's implementation, particularly at the policy level (Clifasefi et al., 2016; Johnson et al., 2012; Trilling, 2016).

Research among those experiencing chronic homelessness is also scant, and questions remain as to how to best link Housing First residents with critical health services. Transportation barriers (Bancroft, 2012), neighborhood security concerns (Hsu et al., 2016), and exclusionary bans from areas surrounding vital services (Bancroft, 2012) may temper treatment accessibility as well as perceptions of choice (Macnaughton et al., 2015). Inhome behavioral health services stand to mitigate some of these barriers. An evaluation of a supportive housing program in Portland, Oregon highlighted associations between offering on-site services, substantial declines in healthcare expenditures, and concurrent reductions in ER use and inpatient treatment (Wright et al., 2016). Excluding studies of Assertive Community Treatment, which emphasizes community-based and in-home services (Aubry et al., 2016) and research demonstrating that integrated auxiliary services improve housing stability and psychiatric symptoms (McHugo et al., 2004), in-home behavioral health research among Housing First participants is limited. This study aimed to address this gap by evaluating outcomes from a novel in-home behavioral health program for Housing First residents with chronic health conditions (including physical health, mental health, and substance misuse).

\section{Methods}

\section{Program Description}

This evaluation examined data from Access to Wellness (ATW), an evidence-based, in-home behavioral health program developed by the AIDS Foundation of Chicago and funded by the Substance Abuse and Mental Health Services Administration (SAMHSA). ATW is a recovery-oriented program constructed to improve the health and stability of individuals confronting chronic homelessness. The program combined a Housing First model with evidence-based behavioral health services delivered in participants' homes.

Program interventions incorporated two evidence-based practices (EBPs) identified by SAMHSA - Screening, Brief Intervention, and Referral to Treatment (SBIRT) and Motivational Interviewing (MI). Trained clinicians delivered SBIRTs in participants' homes. SBIRT is an integrated public health method that comprises three main elements: rapid, standardized screening to assess substance misuse severity and identify appropriate treatment level; brief intervention aimed at fostering participants' awareness and insight into their substance misuse; and referral to substance misuse and mental health treatment as indicated (Substance Abuse and Mental Health Services Administration, 2015). The 
SBIRT strategy has a promising degree of empirical support and is associated with decreased frequency and severity of drug and alcohol use, increased use of specialized substance misuse treatment, and lower rates of ER use and inpatient hospitalization (Aldridge et al., 2017; Gryczynski et al., 2011; Pecoraro et al., 2012).

ATW service providers implemented a modified form of SBIRT which focused on mental health concerns in addition to SBIRT's typical emphasis on problematic substance use. Empirical support for similar modifications is limited; however, Topitzes et al. (2017) altered the SBIRT format to screen for both trauma and alcohol misuse among primary care patients and noted favorably high referral rates to specialized treatment. ATW also incorporated MI techniques to address participants' ambivalence toward seeking traditional substance misuse or mental health services in specialty settings. MI is a client-centered, directive method for enhancing intrinsic motivation to change by exploring and resolving ambivalence (Rollnick \& Miller, 1995).

The ATW program was staffed by a three-person clinical team that included a Mental Illness and Substance Abuse Counselor, a Certified Alcohol and Drug Counselor, and a Registered Nurse. Both clinicians and agency-based case managers (to whom each participant was assigned) were trained to use MI. ATW supplemented these low-threshold EBPs with health assessments and brief mental health or substance misuse counseling provided by study clinicians in participants' homes.

\section{Participants}

One hundred thirty-three participants completed surveys at enrollment. All program participants had at least one chronic physical health condition (including, but not limited to, HIV/AIDS), as well as frequent co-occurring mental health and substance misuse. Prior to program entry, participants were screened to confirm their status as chronically homeless per HUD criteria. Participants resided in scattered-site or project-based apartments in the Chicago area. The sample had slightly more men $(53 \%)$ than women $(47 \%)$ and was primarily African American (69\%). Participants ranged in age from 20 to 72, with a mean of 46 years. Monthly income was low at enrollment $(M=\$ 984, M d n=\$ 952)$ and remained low at 6-month follow-up $(M=\$ 1067, M d n=\$ 974)$. Disability benefits (Social Security Disability Income or Supplemental Security Income) and other forms of public assistance were the most common income sources. A majority of participants $(82 \%)$ had mental health symptoms at enrollment, while $45 \%$ had substance misuse symptoms, and $39 \%$ had cooccurring disorder symptoms.

\section{Procedure}

Trained evaluators administered paper-pencil versions of the Center for Substance Abuse Treatment Government Performance and Results Act (GPRA) tool at program enrollment and 6-months and 12-months post-enrollment (SAMHSA, 2012). Evaluators compensated participants with incentives for their time (gift cards valued at $\$ 10$ at baseline and \$20 for each follow-up). Data were collected for program evaluation and project improvement purposes and released to the study authors for secondary analysis. All data were de-identified and stored on password-protected computers accessible only to the study 
authors. The study received an exempt determination from the principal investigator's university for the secondary analysis.

\section{Variables and Measures}

Participant demographic variables, health variables, and ER and inpatient hospitalization outcomes were included in the analysis and described below. Program use variables (SBIRTs, case management encounters, and mental health and substance misuse counseling treatment hours) were inconsistently reported and exhibited large amounts of missing data, precluding imputation or process evaluation (Saunders et al., 2006; Stefancic et al., 2004).

Demographic variables. Demographic variables were gender, race, age, income, and health insurance status. Participants self-reported gender, race, and insurance status at study enrollment and age and income at both enrollment and 6-month follow-up. Options for gender included male, female, or transgender. Participants could select multiple racial and ethnic categories (African American, Asian American, Native Hawaiian or Pacific Islander, Alaska Native, White, American Indian, and Hispanic or Latino). The researchers dichotomized these responses as African American or Other Race to compensate for low cell counts and to simplify demographic analyses (Murad et al., 2003). Evidence that distinct, systemic factors influence African Americans' entry into homelessness prompted the evaluators to include race as a demographic variable (Jones, 2016). Age was a continuous variable reported in years. Monthly income was also continuous and included income earned from wages; public assistance, retirement, and disability benefits; non-legal sources; financial contributions from friends and family; and other sources. Participants also reported if they had health insurance.

Health variables. Health variables included screening positive or negative for substance misuse symptoms, mental health symptoms, or co-occurring symptoms, using the 16-item self-report Substance Abuse and Mental Illness Symptoms Screener (SAMISS). The SAMISS is a screening instrument designed to identify substance misuse, mood and anxiety disorders. It has an $86 \%$ sensitivity and a $75 \%$ specificity for substance misuse and a $95 \%$ sensitivity and $49 \%$ specificity for mental disorders when compared to the Structured Clinical Interview for DSM-IV (Breuer et al., 2012, 2014).

Outcome variables. Self-report tools assessed participants' ER visits and inpatient hospitalizations at program enrollment and 6- and 12-months post-enrollment. A dichotomous variable indicated if respondents reported ER use or inpatient hospitalization for any reason (physical, mental, or substance misuse) in the 30-days prior to each data collection point. ER visits and inpatient hospitalizations at enrollment and 6-months functioned as the primary outcomes. Neither outcome variable had missing data at enrollment. Ten participants were missing ER and inpatient hospitalization data at 6-month follow-up for the following reasons: discharge for program violation $(n=1)$, discharge due to incarceration $(n=1)$, and missingness for unknown reasons $(n=8)$. Nine additional participants were discharged between 6- and 12-month follow-up for reasons including death $(n=5)$, involuntary discharge for nonparticipation $(n=1)$, involuntary discharge for program violation $(n=1)$, voluntary discharge against staff recommendation $(n=1)$, and 
discharge for unknown reasons $(n=2)$. At 12-month follow-up, inpatient hospitalization data were missing for 43 participants $(32 \%)$ and ER visit data were missing for 44 participants $(33 \%)$ for unknown reasons. To prevent erroneous generalizations from these data (Benston, 2015; Dumville et al., 2006) and in the absence of rigorous explanatory factors to substantiate imputation (Saunders et al., 2006; Thabane et al., 2013), the researchers excluded 12-month follow-up data from the analysis.

\section{Analysis}

Univariate statistics were calculated to describe the sample $(n=133)$. The authors conducted chi-square analyses to compare self-reported ER use and inpatient hospitalization outcomes at baseline and 6-month follow-up for each demographic and health factor. McNemar's chi-square was used for repeated measures analyses. The researchers employed non-parametric tests rather than a technique such as linear regression because ER and inpatient data were not normally distributed (Ghasemi \& Zahediasl, 2012; McHugh, 2013). We also applied maximum likelihood chi-squares when minimum expected cell count assumptions were violated (McHugh, 2013). ER data proved nonnormally distributed based on a significant Shapiro-Wilk value $(p<.001)$, skewness of -0.17 $(S E=0.22)$ and kurtosis of $4.72(S E=0.43)$. Inpatient data was also non-normally distributed as evidenced by a significant Shapiro-Wilk value $(p<.001)$, skewness of $4.04(S E=0.22)$, and kurtosis of 31.39 ( $S E=0.43$ ). After excluding participants with missing data, a smaller sample $(n=123)$ was available for repeated measures analysis. Bivariate results highlighted relationships that were statistically significant $(p<.05)$ or marginally significant $(p<.10)$ (Dahiru, 2008; Wainer \& Robinson, 2003). Due to sample size limitations, multivariate analyses were not conducted.

\section{Results}

Univariate and bivariate analyses are depicted in Table 1. During the 30 days preceding baseline data collection, $17 \%$ of participants reported ER visits and $11 \%$ reported inpatient hospitalizations. By 6-month follow-up, 24\% of participants reported ER visits and 11\% reported inpatient hospitalizations. Chi-square analysis underscored an assortment of marginally significant associations within these data. Changes in ER use between program enrollment and 6-month-follow-up were not statistically significant according to McNemar's chi-square test. No psychiatric symptoms were associated with ER visits or inpatient hospitalizations at either intake or 6-month follow-up.

Several variables maintained marginally significant $(p<.10)$ associations with acute care outcomes. For instance, participants with inpatient hospitalizations at enrollment were males $(73 \%)$ by a marginally significant majority above females $(27 \%), \chi^{2}(1, n=132)=$ $2.80, p=.094, V=.15$. This gender disparity continued at 6-month follow-up, at which time males were responsible for $71 \%$ of inpatient visits and females for $29 \%$ of inpatient visits, $\chi^{2}(1, n=122)=2.91, p=.088, V=.15$. Gender was not related to ER visits. At enrollment (but not at 6-month-follow-up), African Americans composed a higher proportion of inpatient hospitalization users $(87 \%)$ than other racial groups $(13 \%)$, maximum likelihood ratio $\chi^{2}(1, n=133)=2.78, p=.095, V=.135$. 
Table 1. Univariate Analysis of Sample Descriptives and Bivariate Analysis of Inpatient Visits and ER Visits Collected at Intake and Six Months

\begin{tabular}{|c|c|c|c|c|c|}
\hline \multirow[b]{3}{*}{ Independent Variables } & \multicolumn{5}{|c|}{$\mathrm{n}(\%)$} \\
\hline & \multirow[b]{2}{*}{$\begin{array}{c}\text { Sample } \\
n(\%)\end{array}$} & \multicolumn{2}{|c|}{ Intake } & \multicolumn{2}{|c|}{6 Months } \\
\hline & & $\begin{array}{c}\text { Inpatient Hospital } \\
\text { Visits }(n=15,11 \%)\end{array}$ & $\begin{array}{c}\text { ER Visits } \\
(n=22,17 \%) \\
\end{array}$ & $\begin{array}{c}\text { Inpatient Hospital } \\
\text { Visits }(n=14,11 \%) \\
\end{array}$ & $\begin{array}{c}\text { ER Visits } \\
(n=29,24 \%)\end{array}$ \\
\hline Gender: Male (Cisgender) & $70(53 \%)$ & $11(73 \%)^{*}$ & $9(41 \%)$ & $10(71 \%)^{*}$ & $15(52 \%)$ \\
\hline Race: African American & $92(69 \%)$ & $13(87 \%)^{*}$ & $14(64 \%)$ & $12(86 \%)$ & $19(65.5 \%)$ \\
\hline Insured at Intake & $62(63 \%)$ & $11(85 \%)^{*}$ & $11(73 \%)$ & $7(70 \%)$ & $16(70 \%)$ \\
\hline $\begin{array}{l}\text { Mental Health Problem } \\
\text { Screened Positive Intake } \\
\text { Screened Positive } 6 \text { mo. }\end{array}$ & $\begin{array}{l}108(81 \%) \\
95(78 \%)\end{array}$ & $\begin{array}{c}13(87 \%) \\
--\end{array}$ & $\begin{array}{c}20(91 \%) \\
--\end{array}$ & $\begin{array}{l}11(79 \%) \\
11(85 \%)\end{array}$ & $\begin{array}{l}25(86 \%) \\
25(86 \%)\end{array}$ \\
\hline $\begin{array}{l}\text { Substance Abuse Problem } \\
\text { Screened Positive Intake } \\
\text { Screened Positive } 6 \text { mo. }\end{array}$ & $\begin{array}{l}59(44 \%) \\
39(32 \%)\end{array}$ & $\begin{array}{c}8(53 \%) \\
--\end{array}$ & $\begin{array}{c}10(46 \%) \\
--\end{array}$ & $\begin{array}{l}8(57 \%) \\
6(46 \%)\end{array}$ & $\begin{array}{l}12(41 \%) \\
8(30 \%)\end{array}$ \\
\hline $\begin{array}{l}\text { Dual Disorder Problem } \\
\text { Screened Positive Intake } \\
\text { Screened Positive } 6 \text { mo. }\end{array}$ & $\begin{array}{l}52(39 \%) \\
36(30 \%) \\
\end{array}$ & $\begin{array}{c}8(53 \%) \\
-- \\
\end{array}$ & $\begin{array}{c}10(46 \%) \\
-- \\
\end{array}$ & $\begin{array}{l}7(50 \%) \\
6(46 \%) \\
\end{array}$ & $\begin{array}{c}10(34 \%) \\
8(30 \%) \\
\end{array}$ \\
\hline & \multicolumn{5}{|c|}{ M (range) } \\
\hline Age (years) & $46(20-72)$ & $49(24-71)$ & $43(23-57)$ & $50(33-61)$ & $47(23-61)$ \\
\hline $\begin{array}{l}\text { Monthly Income }(\$) \\
\text { At Intake } \\
\text { At } 6 \text { mo. }\end{array}$ & $\begin{array}{l}\$ 984(\$ 91-2606) \\
\$ 1067(\$ 0-2607) \\
\end{array}$ & $\begin{array}{c}\$ 1159(\$ 0-1973) \\
--\end{array}$ & $\begin{array}{c}\$ 1111(\$ 0-2252) \\
--\end{array}$ & $\begin{array}{l}\$ 1009(\$ 0-1585) \\
\$ 1063(\$ 0-1659)\end{array}$ & $\begin{array}{l}\$ 1025(\$ 0-2359) \\
\$ 1195(\$ 0-2607)\end{array}$ \\
\hline
\end{tabular}


Insured participants constituted a higher proportion $(85 \%)$ of those hospitalized at intake than uninsured participants $(15 \%)$, maximum likelihood ratio $\chi^{2}(1, n=98)=3.30, p$ $=.069, V=.173$; this relationship was absent at 6-month-follow-up. Furthermore, being insured was not associated with ER utilization. Finally, neither participant age nor income was associated with ER use or hospitalization.

\section{Discussion}

Although the proportion of ATW ER users increased (from $17 \%$ to $24 \%$ ) between baseline and follow-up, neither ER visits nor inpatient hospitalizations displayed statistically significant changes. Generally, Housing First residents' health stabilizes over time (Jaworsky et al., 2016), so the distinction between current findings and extant research could be salient. Twelve-month data exclusion and the resulting brevity of the study's follow-up period (6 months) compared with prior research (e.g., Leff et al., 2009) may have contributed to the absence of statistically significant acute care changes. Outcomes could also be an artifact of a floor effect, signifying that more sensitive measures are needed. That said, we suggest that the lack of a significant increase in acute care use may denote a short-term stabilization effect given the poor health trajectories of many formerly homeless individuals, even after permanent supportive housing enrollment (Henwood et al., 2015; 2018).

By monitoring participants who use acute care services post-enrollment, Housing First program managers and service providers could begin to identify if participants possess distinctive features, targeting services accordingly. Kerman et al. (2018) identified subgroups of Housing First consumers who - similar to the present study's participants did not display diminished service utilization after Housing First enrollment and argued that consumers' discrepant housing stability levels mediated these differences. Consequently, housing stability measures may enhance outcome monitoring and service planning among social workers practicing in a Housing First context. Using assessment tools to systematically evaluate consumers' individualized needs and collaboratively and responsively allocate services is consistent with the ethos of evidence-based social work practice (Chonody \& Teater, 2018; Drisko, 2014). This practice also embodies social workers' ethical responsibility to practice in a manner that maximizes consumer selfdetermination and demonstrates competence and commitment to clients (National Association of Social Workers, 2017). Because Housing First is an inherently flexible model - in contrast, for example, to manualized interventions - finding ways of efficiently and effectively tailoring services to meet Housing First residents' varying needs is a priority area for further social work research and practice (Henwood, Cabassa, et al., 2013).

Gender differences were notable, if not generalizable, in our evaluation-specifically, cisgender males' elevated inpatient use. Evidence for systematic gender differences in hospitalization among Housing First residents (Srebnik et al., 2013) and the utility of tailoring programs to address sociodemographic differences is inconclusive (Peressini, 2007). Male ATW participants' elevations in inpatient hospitalization may stem from an increased incidence of health problems that necessitated admission but were not captured by study tools. Obtaining consumers' consent to coordinate care between area hospitals and housing services could improve social work practice by enhancing interprofessional 
collaboration and the continuity of care, as well as clarify the possible sources of this gender discrepancy. A group of Australian investigators noted that involving hospital staff more seamlessly in supportive housing was associated with reductions in hospitalizations (Wood et al., 2019). Likewise, comparisons of programs integrating housing and auxiliary services with scattered services reinforce the importance of service integration, especially among males (McHugo et al., 2004).

Relationships between race and hospitalization also differ across studies. For instance, white, homeless women who misused substances exhibited higher rates of hospitalization than other racial groups in an investigation conducted by Gelberg et al. (2009), but disparities diminished after controlling for vulnerability factors (e.g., psychiatric hospitalization, abuse history, pregnancy). In the present evaluation, African American consumers had higher levels of inpatient hospitalization at enrollment but not at 6-month follow- up. Though ATW services may have reduced repeat hospitalization among African Americans, some evidence suggests that housing stability itself is associated with improved health outcomes (Jaworsky et al., 2016; Kerman et al., 2018). This is important to consider in light of the over-representation of African Americans among people experiencing homelessness. In 2019, HUD found that African Americans composed 40\% of the homeless population but only 13\% of the US population (Henry et al., 2020). Further research and evaluation could establish if ATW lowered engagement barriers associated with perceived racial stigma and service avoidance (Skosireva et al., 2014; Weisz \& Quinn, 2018) with aims to adopt anti-oppressive practices at both the direct practice and systems level (Stergiopoulos et al., 2016).

In contrast to our predictions, substance misuse and co-occurring symptoms were not significantly related to ER visits or hospitalizations. Persons navigating homelessness with substance misuse and co-occurring disorders are historically prone to ER visits and hospitalizations, even relative to other chronically ill individuals (Lin et al., 2015; Minassian et al., 2013). Access to in-home behavioral health services and permanent supportive housing appears to have stabilized or, for some subgroups (African Americans), reduced ER and inpatient use. If these findings are reflective of lower psychiatric morbidity among ATW consumers, they could also inform the nature of ATW's services. For example, MI experts suggest that MI appears less effective — or potentially even contraindicatedamong those demonstrating readiness for change, suggesting that as ATW consumers' behavioral health stabilizes, alternative interventions may become more appropriate (Hettema et al., 2004).

Insured participants' elevated rates of hospitalization at enrollment may result from lowering treatment barriers that typically persist for those living as homeless, despite obtaining access to health insurance. Indeed, other investigators found that publicly insured individuals experiencing homelessness use both more ambulatory and acute care services - even in nations offering universal healthcare (Hwang et al., 2013; Lin et al., 2015). By including pre-enrollment and post-enrollment insurance data, ATW could clarify if consumers who are uninsured before enrollment account for a disproportionate number of hospitalizations and whether those stabilize over time. If this trend exists, it might suggest that high baseline hospitalizations are a function of addressing previously unmet healthcare needs. If supported, this finding could impact social work evaluation and 
practice, suggesting that lacking insurance pre-enrollment is an indicator that a participant may benefit from additional staff support. In addition to linking participants to health insurance resources, this support should include referring service users to free or low-cost preventative care and screening programs to identify and treat underlying health conditions. Federally qualified health centers and clinics funded through the Health Care for the Homeless program offer excellent resources for linking currently or formerly homeless individuals to essential healthcare services (Zlotnick et al., 2013).

\section{Limitations}

This program evaluation study has several limitations. The evaluation relied on program data collected and entered by a large team of staff across multiple locations, limiting the researchers' oversight of collection procedures and resulting in considerable missing data for some variables. Missing data and the small size of the sample prevented multivariate analyses and led to the exclusion of both behavioral health intervention data (relating to SBIRTs, case management interventions, etc.) and 12-month follow-up outcomes from data analyses. Regardless of associations between demographic variables and hospitalizations within the ATW data, the evaluation's methodology prohibits causal inferences and prevents the evaluators from dismantling which factors (e.g., housing, inhome behavioral health, demographic factors) mediated outcomes. Another limitation lies in our operationalization of chronic homelessness. In 2015, after data collection supporting the present evaluation ceased, HUD adopted a revised definition of chronic homelessness which required discrete episodes to meet or exceed a 12-month aggregate (U.S. Department of Housing and Urban Development, 2015). The revised definition captured the heaviest users of shelters and, in effect, targeted those most in need of housing support (Byrne \& Culhane, 2015). Since the former definition served as an inclusion criterion, program participants may comprise a group less prone to housing instability than chronically homeless individuals under the current definition (Byrne \& Culhane, 2015). Program effectiveness may be resultantly understated, as Housing First now targets higher-risk persons than during data collection.

The exclusion of fidelity measurements for behavioral health interventions represents another study limitation, meaning that SBIRT or MI interventions may have varied in their adherence to evidence-based protocols. While challenges to ensuring treatment fidelity in a supportive housing environment are not exclusive to the ATW program, the issue is nonetheless deserving of attention based on potential treatment outcome implications (McGraw et al., 2010). Several fidelity measures for SBIRT and MI do exist for application to future research and practice, although they are in varying stages of development and psychometric validation (Moyers et al., 2005, 2016; Pantalon et al., 2012; Vendetti et al., 2017).

Self-report biases are a fundamental concern to researchers of homeless health disparities (Gelberg \& Siecke, 1997). Factors associated with under- or over-reporting of health care use among homeless research participants include recall period (Clifasefi et al., 2011; Somers et al., 2016), alcohol use severity (Clifasefi et al., 2011), service type (e.g. psychiatric hospitalization or ER use; Somers et al., 2016), an active mental health diagnosis (Hwang et al., 2016), and homelessness chronicity of two years or greater 
(Somers et al., 2016). Despite these factors, Hwang et al. (2016) and Somers et al. (2016) supported the use of self-reports with the homeless population, citing their overall consistency with administrative records.

\section{Conclusion}

Chronic homelessness is a potent risk factor for repeat hospitalization, which ambulatory care alone does not adequately address. Housing First inverts treatment-asusual by prioritizing permanent supportive housing without requiring psychiatric stabilization, lowering morbidity and mortality rates. Consumers' relatively low rate of ER use and hospitalization is noteworthy, considering that all consumers had chronic physical health or psychiatric diagnoses, perhaps reflecting the potency of addressing structural barriers via in-home behavioral health services. Males' marginally higher inpatient use may merit tailored services, although program administrators and direct service staff should continue to monitor these outcomes to see if they persist. Reductions in African Americans' inpatient use also warrant ongoing evaluation to determine if they are sustained by current ATW consumers or are reproducible among future cohorts. Subsequent research should employ fidelity metrics and more robust designs, such as randomized controls, to compare outcomes for Housing First residents receiving in-home health services to usual care (linking participants with community providers). Such research could inform the design of evidence-based service packages to reduce hospital use and improve health outcomes. This issue remains critical as the social work profession strives to reduce health disparities and ensure health equity for marginalized groups, including formerly homeless individuals enrolled in Housing First programs.

\section{References}

Aldridge, A., Linford, R., \& Bray, J. (2017). Substance use outcomes of patients served by a large US implementation of Screening, Brief Intervention and Referral to Treatment (SBIRT). Addiction, 112(S2), 43-53. https://doi.org/10.1111/add.13651

American Psychiatric Association. (2000). Diagnostic and statistical manual of mental disorders: DSM-IV-TR (4th ed., text revision.). Author.

Aubry, T., Farrell, S., Hwang, S. W., \& Calhoun, M. (2013). Identifying the patterns of emergency shelter stays of single individuals in Canadian cities of different sizes. Housing Studies, 28(6), 910-927. https://doi.org/10.1080/02673037.2013.773585

Aubry, T., Goering, P., Veldhuizen, S., Adair, C. E., Bourque, J., Distasio, J., Latimer, E., Stergiopoulos, V., Somers, J., Streiner, D. L., \& Tsemberis, S. (2016). A multiple-city RCT of Housing First with Assertive Community Treatment for homeless Canadians with serious mental illness. Psychiatric Services, 67(3), 275-281. https://doi.org/ 10.1176/appi.ps.201400587

Bancroft, K. H. (2012). Zones of exclusion: Urban spatial policies, social justice, and social services. Journal of Sociology and Social Welfare, 39(3), 63-84. https://scholarworks.wmich.edu/jssw/vol39/iss3/5 
Benston, E. A. (2015). Housing programs for homeless individuals with mental illness: Effects on housing and mental health outcomes. Psychiatric Services, 66(8), 806-816. https://doi.org/10.1176/appi.ps.201400294

Blanchard, K. A., Morgenstern, J., Morgan, T. J., Lobouvie, E. W., \& Bux, D. A. (2003). Assessing consequences of substance use: Psychometric properties of the Inventory of Drug Use Consequences. Psychology of Addictive Behaviors, 17(4), 328-331. https://doi.org/10.1037/0893-164X.17.4.328

Boothroyd, R. A., \& Chen, H. J. (2008). The psychometric properties of the Colorado Symptom Index. Administration and Policy in Mental Health, 35(5), 370-378. https://doi.org/10.1007/s10488-008-0179-6

Breuer, E., Stoloff, K., Myer, L., Seedat, S., Stein, D. J., \& Joska, J. (2012). Reliability of the lay adherence counsellor administered Substance Abuse and Mental Illness Symptoms Screener (SAMISS) and the International HIV Dementia Scale (IHDS) in a primary care HIV clinic in Cape Town, South Africa. AIDS and Behavior, 16(6), 1464-1471. https://doi.org/10.1007/s10461-011-0067-z

Breuer, E., Stoloff, K., Myer, L., Seedat, S., Stein, D. J., \& Joska, J. A. (2014). The validity of the Substance Abuse and Mental Illness Symptom Screener (SAMISS) in people living with HIV/AIDS in primary HIV care in Cape Town, South Africa. AIDS and Behavior, 18(6), 1133-1141. https://doi.org/10.1007/s10461-014-0698-y

Brown, M. M., Jason, L. A., Malone, D. K., Srebnik, D., \& Sylla, L. (2016). Housing First as an effective model for community stabilization among vulnerable individuals with chronic and nonchronic homelessness histories. Journal of Community Psychology, 44(3), 384-390. https://doi.org/10.1002/jcop.21763

Byrne, T., \& Culhane, D. P. (2015). Testing alternative definitions of chronic homelessness. Psychiatric Services, 66(9), 996-999. https://doi.org/10.1176/appi.ps. $\underline{201400240}$

Chonody, J. M., \& Teater, B. (2018). Exploring how practicing social workers define evidence-based practice. Advances in Social Work, 18(4), 1237-1249. https://doi.org/10.18060/22075

Chwastiak, L., Tsai, J., \& Rosenheck, R. (2012). Impact of health insurance status and a diagnosis of serious mental illness on whether chronically homeless individuals engage in primary care. American Journal of Public Health, 102(12), e83-e89. https://doi.org/10.2105/AJPH.2012.301025

Clifasefi, S. L., Collins, S. E., Tanzer, K., Burlingham, B., Hoang, S. E., \& Larimer, M. E. (2011). Agreement between self-report and archival public service utilization data among chronically homeless individuals with severe alcohol problems. Journal of Community Psychology, 39(6), 631-644. https://doi.org/10.1002/jcop.20457

Clifasefi, S. L., Collins, S. E., Torres, N. I., Grazioli, V. S., \& Mackelprang, J. L. (2016). Housing first, but what comes second? A qualitative study of resident, staff and 
management perspectives on single-site housing first program enhancement. Journal of Community Psychology, 44(7), 845-855. https://doi.org/10.1002/jcop.21812

Dahiru, T. (2008). P-value, a true test of statistical significance? A cautionary note. Annals of Ibadan Postgraduate Medicine, 6(1), 21-26. https://doi.org/10.4314/aipm. v6i1.64038

Drisko, J. (2014). Research evidence and social work practice: The place of evidencebased practice. Clinical Social Work Journal, 42(2), 123-133. https://doi.org/10.1007/ s10615-013-0459-9

Dumville, J. C., Torgerson, D. J., \& Hewitt, C. E. (2006). Reporting attrition in randomised controlled trials. British Medical Journal, 332(7547), 969-971. https://doi.org/10.1136/ bmj.332.7547.969

Fazel, S., Khosla, V., Doll, H., \& Geddes, J. (2008). The prevalence of mental disorders among the homeless in Western countries: Systematic review and meta-regression analysis. PLoS Medicine, 5(12), 1670-1681. https://doi.org/10.1371/journal.pmed. $\underline{0050225}$

Folsom, D. P., Hawthorne, W., Lindamer, L., Gilmer, T., Bailey, A., Golshan, S., Garcia, P., Unützer, J., Hough, R., \& Jeste, D. V. (2005). Prevalence and risk factors for homelessness and utilization of mental health services among 10,340 patients with serious mental illness in a large public mental health system. American Journal of Psychiatry, 162(2), 370-376. https://doi.org/10.1176/appi.ajp.162.2.370

Gelberg, L., Andersen, R., Longshore, D., Leake, B., Nyamathi, A., Teruya, C., \& Arangua, L. (2009). Hospitalizations among homeless women: Are there ethnic and drug abuse disparities? Journal of Behavioral Health Services \& Research, 36(2), 212-232. https://doi.org/10.1007/s11414-008-9144-0

Gelberg, L., \& Siecke, N. (1997). Accuracy of homeless adults' self-reports. Medical Care, 35(3), 287-290. https://www.jstor.org/stable/3766875?seq $=18$

Ghasemi, A., \& Zahediasl, S. (2012). Normality tests for statistical analysis: A guide for non-statisticians. International Journal of Endocrinology and Metabolism, 10(2), 486-489. https://doi.org/10.5812/ijem.3505

Greenwood, R. M., Schaefer-McDaniel, N. J., Winkel, G., \& Tsemberis, S. J. (2005). Decreasing psychiatric symptoms by increasing choice in services for adults with histories of homelessness. American Journal of Community Psychology, 36(3-4), 224-238. https://doi.org/10.1007/s10464-005-8617-z

Groton, D. (2013). Are Housing First programs effective? A research note. Journal of Sociology and Social Welfare, 40(1), 51-63. https://scholarworks.wmich.edu/ jssw/vol40/iss1/4

Gryczynski, J., Mitchell, S. G., Peterson, T. R., Gonzales, A., Moseley, A., \& Schwartz, R. P. (2011). The relationship between services delivered and substance use outcomes in New Mexico's Screening, Brief Intervention, Referral and Treatment (SBIRT) 
Initiative. Drug and Alcohol Dependence, 118(2), 152-157. https://dx.doi.org/ $\underline{10.1016 \% 2 F j . d r u g a l c d e p .2011 .03 .012 ~}$

Henry, M., Watt, R., Mahathey, A., Ouellette, J., Sitler, A., \& Associates, A. (2020). The 2019 Annual Homelessness Assessment Report (AHAR) to Congress, Part 1: Pointin-time estimates of homelessness. https://files.hudexchange.info/resources/ documents/2019-AHAR-Part-1.pdf

Henwood, B. F., Byrne, T., \& Scriber, B. (2015). Examining mortality among formerly homeless adults enrolled in Housing First: An observational study. BMC Public Health, 15(1), 1209. https://doi.org/10.1186/s12889-015-2552-1

Henwood, B. F., Cabassa, L. J., Craig, C. M., \& Padgett, D. K. (2013). Permanent supportive housing: Addressing homelessness and health disparities? American Journal of Public Health, 103(S2), S188-S192. https://doi.org/10.2105/ ajph.2013.301490

Henwood, B. F., Hsu, H., Dent, D., Winetrobe, H., Carranza, A., \& Wenzel, S. (2013). Transitioning from homelessness: A "Fresh-start" event. Journal of the Society for Social Work and Research, 4(1), 47-57. https://doi.org/10.5243/jsswr.2013.4

Henwood, B. F., Lahey, J., Rhoades, H., Winetrobe, H., \& Wenzel, S. L. (2018). Examining the health status of homeless adults entering permanent supportive housing. Journal of Public Health, 40(2), 415-418. https://doi.org/10.1093/ pubmed/fdx069

Hettema, J., Steele, J., \& Miller, W. R. (2004). Motivational interviewing. Annual Review of Clinical Psychology, 1(1), 91-111. https://doi.org/10.1146/annurev.clinpsy.1.102803. 143833

Hsu, H.-T., Simon, J. D., Henwood, B. F., Wenzel, S. L., \& Couture, J. (2016). Location, location, location: Perceptions of safety and security among formerly homeless persons transitioned to permanent supportive housing. Journal of the Society for Social Work and Research, 7(1), 65-88. https://doi.org/10.1086/685034

Hwang, S. W., Chambers, C., Chiu, S., Katic, M., Kiss, A., Redelmeier, D. A., \& Levinson, W. (2013). A comprehensive assessment of health care utilization among homeless adults under a system of universal health insurance. American Journal of Public Health, 103 Suppl 2(0 2), S294-S301. https://doi.org/10.2105/AJPH.2013.301369

Hwang, S. W., Chambers, C., \& Katic, M. (2016). Accuracy of self-reported health care use in a population-based sample of homeless adults. Health Services Research, 51(1), 282-301. https://doi.org/10.1111/1475-6773.12329

Jaworsky, D., Gadermann, A., Duhoux, A., Naismith, T. E., Norena, M., To, M. J., Hwang, S. W., \& Palepu, A. (2016). Residential stability reduces unmet health care needs and emergency department utilization among a cohort of homeless and vulnerably housed persons in Canada. Journal of Urban Health, 93(4), 666-681. https://doi.org/10.1007/s11524-016-0065-6 
Johnson, G., Parkinson, S., \& Parsell, C. (2012). Policy shift or program drift? Implementing Housing First in Australia [AHURI Final Report No. 184]. Australian Housing and Urban Research Institute. https://www.ahuri.edu.au/_data/assets/ pdf_file/0012/2064/AHURI_Final_Report_No184_Policy_shift_or_program_drift_I mplementing_Housing_First in Australia.pdf

Jones, M. M. (2016). Does race matter in addressing homelessness? A review of the literature. World Medical and Health Policy, 8(2), 139-156. https://doi.org/ $\underline{10.1002 / \mathrm{wmh} 3.189}$

Kerman, N., Sylvestre, J., Aubry, T., \& Distasio, J. (2018). The effects of housing stability on service use among homeless adults with mental illness in a randomized controlled trial of housing first. BMC Health Services Research, 18(190), 1-14. https://doi.org/10.1186/s12913-018-3028-7

Khandor, E., Mason, K., Chambers, C., Rossiter, K., Cowan, L., \& Hwang, S. W. (2011). Access to primary health care among homeless adults in Toronto, Canada: Results from the street health survey. Open Medicine, 5(2), 94-103. https://www.ncbi.nlm. nih.gov/pmc/articles/PMC3148004/

Ku, B. S., Scott, K. C., Kertesz, S. G., \& Pitts, S. R. (2010). Factors associated with use of urban emergency departments by the U.S. homeless population. Public Health Reports, 125(3), 398-405. https://doi.org/10.1177/003335491012500308

Larimer, M. E., Malone, D. K., Garner, M. D., Atkins, D. C., Burlingham, B., Lonczak, H. S., Tanzer, K., Ginzler, J., Clifasefi, S. L., Hobson, W. G., \& Marlatt, G. A. (2009). Health care and public service use and costs before and after provision of housing for chronically homeless persons with severe alcohol problems. Journal of the American Medical Association, 301, 1349-1357. https://jamanetwork.com/journals/jama/fullarticle/183666

Leff, H. S., Chow, C. M., Pepin, R., Conley, J., Allen, I. E., \& Seaman, C. A. (2009). Does one size fit all? What we can and can't learn from a meta-analysis of housing models for persons with mental Illness. Psychiatric Services, 60(4), 473-482. https://ps.psychiatryonline.org/doi/full/10.1176/ps.2009.60.4.473

Lin, W. C., Bharel, M., Zhang, J., O'Connell, E., \& Clark, R. E. (2015). Frequent emergency department visits and hospitalizations among homeless people with Medicaid: Implications for Medicaid expansion. American Journal of Public Health, 105(S5), S716-S722. https://doi.org/10.2105/AJPH.2015.302693

Lippert, A. M., \& Lee, B. A. (2015). Stress, coping, and mental health differences among homeless people. Sociological Inquiry, 85(3), 343-374. https://doi.org/ $\underline{10.1111 / \text { soin. } 12080}$

Macnaughton, E., Stefancic, A., Nelson, G., Caplan, R., Townley, G., Aubry, T., McCullough, S., Patterson, M., Stergiopoulos, V., Vallée, C., Tsemberis, S., Fleury, M.-J., Piat, M., \& Goering, P. (2015). Implementing Housing First across sites and over time: Later fidelity and implementation evaluation of a pan-Canadian multi-site Housing First program for homeless people with mental illness. American Journal of Community Psychology, 55(3), 279-291. https://doi.org/10.1007/s10464-015-9709-z 
McAllister, W., Lennon, M. C., \& Kuang, L. (2011). Rethinking research on forming typologies of homelessness. American Journal of Public Health, 101(4), 596-601. https://doi.org/10.2105/AJPH.2010.300074

McGraw, S. A., Larson, M. J., Foster, S. E., Kresky-Wolff, M., Botelho, E. M., Elstad, E. A., Stefancic, A., \& Tsemberis, S. (2010). Adopting best practices: Lessons learned in the Collaborative Initiative to Help End Chronic Homelessness (CICH). Journal of Behavioral Health Services \& Research, 37(2), 197-212. https://doi.org/10.1007/s11414$\underline{009-9173-3}$

McHugh, M. L. (2013). The Chi-square test of independence. Biochemia Medica, 23(2), 143-149. http://dx.doi.org/10.11613/BM.2013.018

McHugo, G. J., Bebout, R. R., Harris, M., Cleghorn, S., Herring, G., Xie, H., Becker, D., \& Drake, R. E. (2004). A randomized controlled trial of integrated versus parallel housing services for homeless adults with severe mental illness. Schizophrenia Bulletin, 30(4), 969-982. https://doi.org/10.1093/oxfordjournals.schbul.a007146

McLellan, A. T., Luborsky, L., Woody, G. E., \& O'Brien, C. P. (1980). An improved diagnostic evaluation instrument for substance abuse patients: The Addiction Severity Index. Journal of Nervous and Mental Disease, 168(1), 26-33. https://doi.org/ $\underline{10.1097 / 00005053-198001000-00006}$

Minassian, A., Vilke, G. M., \& Wilson, M. P. (2013). Frequent emergency department visits are more prevalent in psychiatric, alcohol abuse, and dual diagnosis conditions than in chronic viral illnesses such as hepatitis and human immunodeficiency virus. Journal of Emergency Medicine, 45(4), 520-525. https://doi.org/10.1016/j.jemermed.2013.05.007

Moyers, T. B., Martin, T., Manuel, J. K., Hendrickson, S. M. L., \& Miller, W. R. (2005). Assessing competence in the use of motivational interviewing. Journal of Substance Abuse Treatment, 28(1), 19-26. https://doi.org/10.1016/j.jsat.2004.11.001

Moyers, T. B., Rowell, L. N. M. S., Manuel, J. K., Ernst, D., \& Houck, J. M. (2016). The Motivational Interviewing Treatment Integrity Code (MITI 4): Rationale, preliminary reliability and validity. Journal of Substance Abuse Treatment, 65, 36-42. https://doi.org/10.1016/j.jsat.2016.01.001

Murad, H., Fleischman, A., Sadetzki, S., Geyer, O., \& Freedman, L. (2003). Small samples and ordered logistic regression: Does it help to collapse categories of outcome? American Statistician, 57(3), 155-160. www.jstor.org/stable/30037262

National Association of Social Workers. (2017). NASW code of ethics. https://www.socialworkers.org/About/Ethics/Code-of-Ethics/Code-of-Ethics-English

Nelson, G. (2010). Housing for people with serious mental illness: Approaches, evidence, and transformative change. Journal of Sociology and Social Welfare, 37(4), 123-146. https://doi.org/10.3868/s050-004-015-0003-8

New Hampshire Dartmouth Psychiatric Research Center. (1995). Drug and Alcohol Follow-Back Calendar. Dartmouth Medical School, Hanover, NH. 
Oppenheimer, S. C., Nurius, P. S., \& Green, S. (2016). Homelessness history impacts on health outcomes and economic and risk behavior intermediaries: New insights from population data. Families in Society, 97(3), 230-242. https://doi.org/10.1606/10443894.2016.97.21

Pantalon, M. V, Martino, S., Dziura, J., Li, F.-L., Owens, P. H., Fiellin, D. A., O'Connor, P. G., \& D'Onofrio, G. (2012). Development of a scale to measure practitioner adherence to a brief intervention in the emergency department. Journal of Substance Abuse Treatment, 43(4), 382-388. https://doi.org/10.1016/j.jsat.2012.08.011

Pecoraro, A., Horton, T., Ewen, E., Becher, J., Wright, P. A., Silverman, B., McGraw, P., \& Woody, G. E. (2012). Early data from Project Engage: A program to identify and transition medically hospitalized patients into addictions treatment. Addiction Science \& Clinical Practice, 7(20), 1-7. https://doi.org/10.1186/1940-0640-7-20

Peressini, T. (2007). Perceived reasons for homelessness in Canada: Testing the heterogeneity hypothesis. Canadian Journal of Urban Research, 16(1), 112-126. https://www.jstor.org/stable/26192529?seq=1

Rog, D. J., Marshall, T., Dougherty, R. H., George, P., Daniels, A. S., Ghose, S. S., \& Delphin-Rittmon, M. E. (2014). Permanent supportive housing: Assessing the evidence. Psychiatric Services, 65(3), 287-294. https://doi.org/10.1176/appi.ps.201300261

Rollnick, S., \& Miller, W. R. (1995). What is motivational interviewing? Behavioural and Cognitive Psychotherapy, 23(4), 325-334. https://doi.org/10.1017/S135246580001643X

Saunders, J. A., Morrow-Howell, N., Spitznagel, E., Dore, P., Proctor, E. K., \& Pescarino, R. (2006). Imputing missing data: A comparison of methods for social work researchers. Social Work Research, 30(1), 19-31. https://doi.org/10.1093/swr/30.1.19

Skosireva, A., O’Campo, P., Zerger, S., Chambers, C., Gapka, S., \& Stergiopoulos, V. (2014). Different faces of discrimination: Perceived discrimination among homeless adults with mental illness in healthcare settings. BMC Health Services Research, 14(376), 1-11. https://doi.org/10.1186/1472-6963-14-376

Sobell, L. C., \& Sobell, M. B. (1992). Timeline Follow-Back. In R. Z. Litten \& J. P. Allen (Eds.), Measuring alcohol consumption: Psychosocial and biochemical methods (pp. 41-72). Humana Press. https://doi.org/10.1007/978-1-4612-0357-5_3

Somers, J. M., Moniruzzaman, A., Currie, L., Rezansoff, S. N., Russolillo, A., \& Parpouchi, M. (2016). Accuracy of reported service use in a cohort of people who are chronically homeless and seriously mentally ill. BMC Psychiatry, 16(41), 1-7. https://doi.org/10.1186/s12888-016-0758-0

Srebnik, D., Connor, T., \& Sylla, L. (2013). A pilot study of the impact of housing firstsupported housing for intensive users of medical hospitalization and sobering services. American Journal of Public Health, 103(2), 316-321. https://doi.org/10.2105/AJPH.2012.300867

Stefancic, A., Schaefer-McDaniel, N. J., Davis, A. C., \& Tsemberis, S. (2004). Maximizing follow-up of adults with histories of homelessness and psychiatric 
disabilities. Evaluation and Program Planning, 27(4), 433-442.

https://doi.org/10.1016/j.evalprogplan.2004.07.006

Stergiopoulos, V., Gozdzik, A., Misir, V., Skosireva, A., Sarang, A., Connelly, J., Whisler, A., \& McKenzie, K. (2016). The effectiveness of a Housing First adaptation for ethnic minority groups: Findings of a pragmatic randomized controlled trial. $B M C$ Public Health, 16(1110), 1-11. https://doi.org/10.1186/s12889-016-3768-4

Substance Abuse and Mental Health Services Administration. (2012). Government Performance and Results Act (GPRA) client outcome measures for discretionary programs. https://www.samhsa.gov/sites/default/files/GPRA/sais_gpra client_outcome instrument_final.pdf

Substance Abuse and Mental Health Services Administration. (2015). About Screening, Brief Intervention, and Referral to Treatment (SBIRT). https://www.samhsa.gov/sbirt/about

Thabane, L., Mbuagbaw, L., Zhang, S., Samaan, Z., Marcucci, M., Ye, C., Thabane, M., Giangregorio, L., Dennis, B., Kosa, D., Debono, V. B., Dillenburg, R., Fruci, V., Bawor, M., Lee, J., Wells, G., \& Goldsmith, C. H. (2013). A tutorial on sensitivity analyses in clinical trials: The what, why, when and how. BMC Medical Research Methodology, 13(92), 1-12. https://doi.org/10.1186/1471-2288-13-92

Topitzes, J., Berger, L., Otto-Salaj, L., Mersky, J. P., Weeks, F., \& Ford, J. D. (2017). Complementing SBIRT for alcohol misuse with SBIRT for trauma: A feasibility study. Journal of Social Work Practice in the Addictions, 17(1-2), 188-215. https://doi.org/10.1080/1533256X.2017.1305392

Trilling, D. (2016). Chronic homelessness and the Housing First program: Research review of how programs have worked. https://journalistsresource.org/studies/society/ housing/chronic-homeless-housing-first-research/

Tsai, J., Mares, A. S., \& Rosenheck, R. A. (2010). A multi-site comparison of supported housing for chronically homeless adults: "Housing first" versus "residential treatment first." Psychological Services, 7(4), 219-232. https://doi.apa.org/doiLanding?doi= $10.1037 \% 2 \mathrm{Fa} 0020460$

U.S. Department of Housing and Urban Development. (2015). Homeless Emergency Assistance and Rapid Transition to Housing: Defining "chronically homeless." Federal Register, 80(233), 75791-75806. https://www.govinfo.gov/content/pkg/FR2015-12-04/pdf/2015-30473.pdf

Vendetti, J. A., McRee, B. G., \& Del Boca, F. K. (2017). Development of the SBIRT checklist for observation in real-time (SCORe). Addiction, 112, 34-42. https://doi.org/10.1111/add.13657

Wadhera, K. R., Choi, W. E., Shen, E. C., Yeh, E. R., \& Joynt Maddox, E. K. (2019). Trends, causes, and outcomes of hospitalizations for homeless individuals: A retrospective cohort study. Medical Care, 57(1), 21-27. https://doi.org/10.1097/ MLR.0000000000001015 
Wainer, H., \& Robinson, D. H. (2003). Shaping up the practice of null hypothesis significance testing. Educational Researcher, 32(7), 22-30. http://www.jstor.org/stable/3699919

Weisz, C., \& Quinn, D. M. (2018). Stigmatized identities, psychological distress, and physical health: Intersections of homelessness and race. Stigma and Health, 3(3), 229-240. https://doi.org/10.1037/sah0000093

White, B. M., Jones, W. J., Moran, W. P., \& Simpson, K. N. (2016). Effect of the economic recession on primary care access for the homeless. Journal of Health Care for the Poor and Underserved, 27(3), 1577-1591. https://doi.org/10.1353/HPU.2016.0104

Wood, L., Wood, N., Vallesi, S., Stafford, A., Davies, A., \& Cumming, C. (2019). Hospital collaboration with a Housing First program to improve health outcomes for people experiencing homelessness. Housing, Care and Support, 22(1), 27-39. https://doi.org/10.1108/HCS-09-2018-0023

Wright, B. J., Vartanian, K. B., Li, H.-F., Royal, N., \& Matson, J. K. (2016). Formerly homeless people had lower overall health care expenditures after moving into supportive housing. Health Affairs, 35(1), 20-27. https://doi.org/10.1377/hlthaff.2015.0393

Zlotnick, C., Zerger, S., \& Wolfe, P. B. (2013). Health care for the homeless: What we have learned in the past 30 years and what's next. American Journal of Public Health, 103 Suppl 2(Suppl 2), S199-S205. https://doi.org/10.2105/AJPH.2013.301586

Author note: Address correspondence to Ryan Savino (rsavino@gradcenter.cuny.edu)

Acknowledgement: The authors would like to thank the AIDS Foundation of Chicago and the Access to Wellness program team for their support. Ryan Savino was affiliated with the University at Buffalo at the time of the study. 